\title{
Automated architecture: violence and nihilism as strategies of 'making' in the tactics of Coop Himmelb(I)au
}

\author{
Michael Chapman and Michael Ostwald
}

\begin{abstract}
The avant-garde architectural culture of the 1980 s was dominated by the movement imperfectly described as Deconstruction and celebrated in the 1988 MoMA exhibition Deconstructivist Architects. Drawing on the work of the French thinker Jacques Derrida, the aim of the architects collected in the exhibition was to destabilise architecture by dismantling accepted notions of space, structure and form. Of the architects who have pursued this mode of enquiry, the Austrian partnership of Coop Himmelb(1)au represent one of the most pervasive models of interrogating space by reducing its conceptualisation to a single moment, captured in sketches and models and then, finally, in architecture. Outside architecture, artists like Gordon Matta-Clark, composers like John Cage and, more esoterically, the evolution of Industrial Punk music, all marked the emergence of this dissatisfaction with architecture and the political systems it symbolically represented. While Deconstruction became the term under which these nihilistic tendencies of 'making' were grouped, many had their genesis much earlier in the revolutionary critical practices of the 1960 s in art, music and philosophy.
\end{abstract}

Deconstruction is just the latest in a long history of theoretical agendas which set out to dismantle the normalising processes of architectural design through a process of orchestrated indeterminacy. Certain themes connect the processes of Deconstruction, and in particular Coop Himmelb(1)au, with earlier avant-garde movements in art, particularly the ideologically driven Dada which emerged towards the end of the First World War in the European city of Zurich before spreading to Cologne, Berlin, New York and Paris. Dada reacted to the widespread cultural pessimism that emerged from the brutality of the First World War, attacking specifically the codes and conventions of normalisation as a means of destabilising culture. Dada used disruptive tactics and indeterminacy as a means of striking out at conventional bourgeoisie taste and the political orthodoxies which accompanied it. The tendency of Dada to reduce creativity to a single, politically charged moment, was later assimilated into the discourse of Surrealism through André Breton's notion of automatism.

This paper will look at the processes of making embodied in the working method of Coop Himmelb(l)au and their relationship to the earlier avant-garde practices of Dada. Using violence and nihilism as key strategies in this subversive attitude towards making, the paper will argue that indeterminacy, as an avant-garde strategy, has a long history as a subversive and politically motivated tactic against architectural hegemony and the taste of the bourgeoisie. The nihilistic impulse that connects certain strands of Deconstruction with Dada provides a platform for revisiting 'ideology' and its relationship to modes of architectural production.

\section{Attacking the architectural object}

A powerful image of a domestic house, plunged through from above with a shiny metal dagger, is the surviving record of Coop Himmelb(1)au's 1978 project Haus Vektor II (also known as House Meier-Hahn) [1]. Recorded in an iconic photograph, the project articulates a radical new relationship between the architect and the architectural object where the cultural values of domesticity and shelter that are manifest in the building's shell are violently attacked from outside. The dagger pierces the delicate outer skin of the house, slicing violently through its central chambers, and dismantling with surgical precision the humanistic associations of dwelling as it emerges triumphantly from the other side. Himmelb(l)au's proposed alterations, existing first as a model, and then as a photograph, not only attack the values of domesticity inscribed in the building's shell, but the architectural object itself and the processes of making which implicate it. ${ }^{1}$

Through a radical reconceptualisation of the process of 'making' architecture, Coop Himmelb(1)au's Vektor Haus establishes a relationship where the architectural object and its production are no longer connected but in a state of mutual friction and internal collapse. The act symbolically establishes the architectural object as a residual home for conventional and conservative 


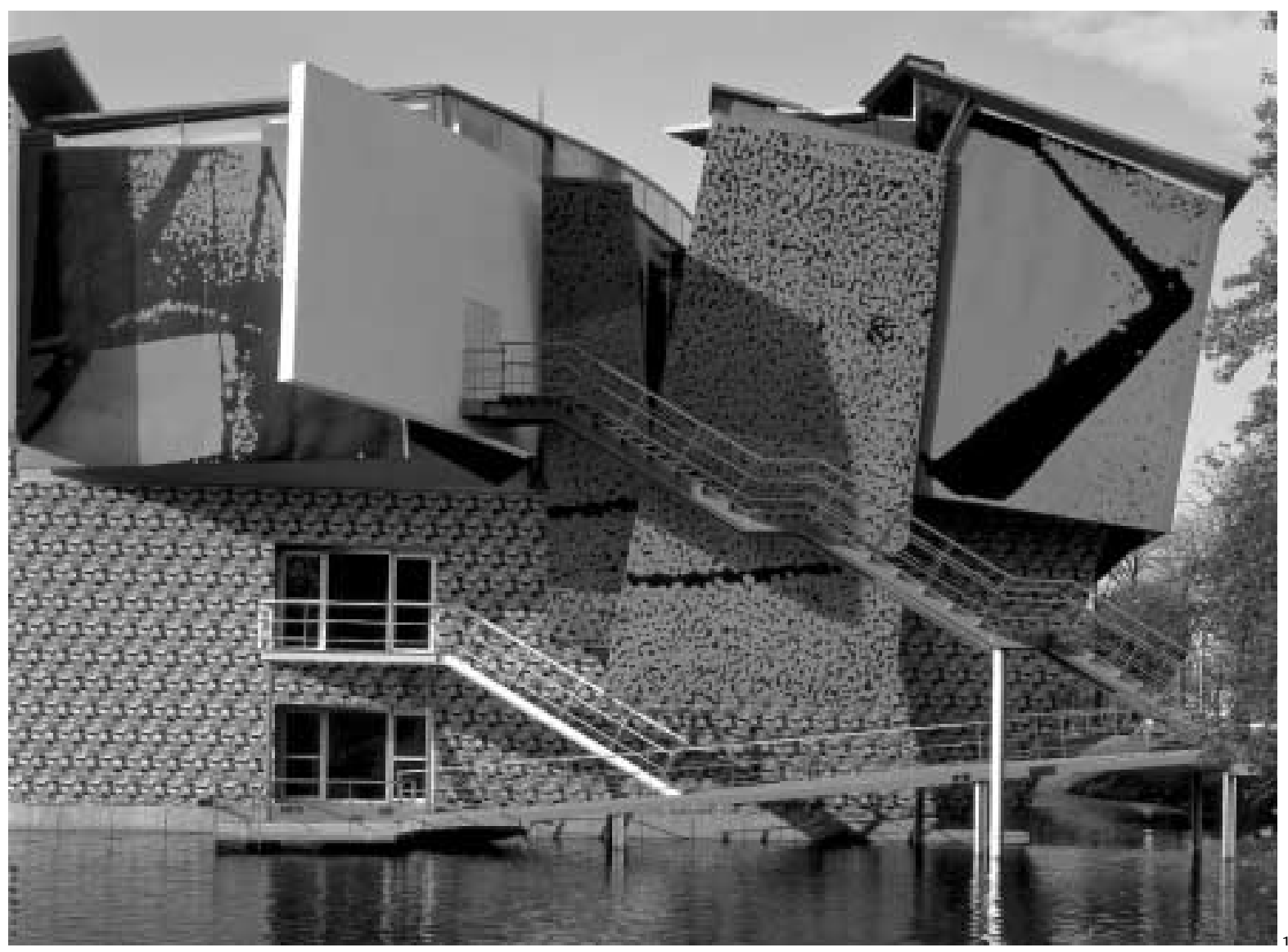

political values which are inevitably accumulated in traditional architectural processes. As the architectural object is increasingly distanced from its author, a critical process emerges where the object, rather than being the outcome of architectural making, becomes its immediate and legitimate target. This distancing of the object from its making was also a theme in post-structuralist theorising on art, as well as conceptual art of the late 1960 s and '7os. Authors such as Lucy Lippard observed the dematerialisation of the art object, embodied in a creative framework where 'method' becomes critical practice, devoid of associations of value or subjective assertions of quality. ${ }^{2}$ Replicating the themes of conceptual art, Himmelb(1)au's violent modifications in the Vector projects delineate a model of architectural investigation as critical practice, whereby the 'method' becomes the work itself, re-establishing a framework through which it, and the object itself, are to be reinterpreted.

\section{Dada and a spirit of experimental practice}

The problematic relationship that exists between the object, the author and the processes of making has been a familiar theme in twentieth-century art, emerging, most dynamically at the end of the First World War, in the radical experiments of the Dada movement. Here the art object, as the accumulation of conventional and conservative practices of artmaking, became the symbolic and tangible target of deliberate nihilistic tendencies. Marcel Duchamp's well-known readymades - such as his 1917 urinal, inverted, given the title 'Fountain' and then signed

\section{Coop Himmelb(l)au, Groninger Museum, the East Pavilion, Groningen, Netherlands (1993-1994)}

under the pseudonym ' $R$. Mutt' - are the canonical representation of this contempt for the object and its accumulated meanings. ${ }^{3}$ Similarly the work of artists like Max Ernst and Hans Arp, as well as the poetry of Tristan Tzara, deliberately deferred creative input into random, indeterminate and often violent acts where the 'artwork' itself becomes incidental to the processes of its making. Emerging from the cultural pessimism of the First World War, these practices used violence as a means of destabilising established notions of art and dismantling its inherited meanings. The tactics of Dada were central to the evolution of conceptual art in the 196os, where the art object was further problematised by an emerging intellectual culture in America which used the Dada ethos to question the institutional values of mainstream artistic practice. Despite clear cultural and historical differences, strong connections also exist between the working methods of Dada and the earliest work of Coop Himmelb(l)au. The firm's fascination with violence, widespread use of collage, hastily constructed models and short and vitriolic manifestoes demonstrate a resonance, in both style and substance, with the earlier nihilistic avant-garde tactics of Dada.

The working processes of Coop Himmelb(1)au have been subjected to a vast array of critical attention over the last decades since they came to 
international prominence, primarily through the widespread publication of their Rooftop Remodelling project in Vienna (1983) and their inclusion in the high-profile Deconstructivist Architects exhibition in New York in 1988. ${ }^{4}$ Anthony Vidler has established Coop Himmelb(1)au as one of a number of recent practices which, in unison, constitute a 'third' paradigm in the historical relationship between the body and architecture: the first two being Vitruvian Classicism and, following that, physiognomy which dominates the theorising of the French Enlightenment. ${ }^{5}$ For Vidler the work of Coop Himmelb(1)au can be aligned with an anti-humanist tendency which seeks violently to dismantle the relationship between the body and architecture and is a characteristic of avant-garde practices of the late twentieth century. The implications of stabbing, puncturing and piercing which are manifest in the Vector projects provide a clear correlation with this tendency to destabilise the body as the logocentric origin of architectural form in Himmelb(l)au's often quoted pursuit of:

'[a]rchitecture that bleeds, that exhausts, that whirls, and even breaks. Architecture that lights up, stings, rips and tears under stress. ${ }^{6}$

As well as focusing on the bodily metaphors inscribed in Coop Himmelb(l)au's architecture, critical attention has also been placed on the working method of the firm which sets out to distil architecture into a single moment, frozen in the initial sketch for a building - its 'psychogram' - and its incarnation in a simultaneously constructed model. This process, which also embodies the bodily gesture as a means of extracting architectural form, culminates in their Groninger Museum project where the initial sketch is etched onto the side of the building so that, as the steel rusts away, the only element left of the building is the sketch.7 The process thus links poetically the building's destiny with its origin [2].

\section{Destructive tactics}

What follows examines how these processes of 'making' architecture can be interpreted, not only within the context of the body but within the broader framework of avant-garde theories of art which emerged at around the same time. The paper will draw on recent critical art theory to demonstrate the way that connections may be drawn between Coop Himmelb(1)au's approach to the production of architecture and avant-garde theories of critical practice. Establishing connections with the 'neo-avant-garde' in art of the 196os, a critical approach will be discussed relating to earlier avantgarde themes in the work of Himmelb(l)au and their incarnation in the firm's idiosyncratic and highly politicised approach to making architecture. The Vektor Haus project will provide a backdrop to this investigation, as symptomatic of the architectural moment whereby these processes are made manifest. The violent alteration embodied in the Vektor Haus of 1979 is representative of the themes that had preoccupied the practice of Coop Himmelb(l)au until that point. Replicated in a number of projects from this period as well as their increasingly violent manifestoes, the notions of 'stabbing', 'ripping', 'plunging, 'tearing' and 'piercing, ${ }^{\text {are recurring }}$ themes running through the work of Himmelb(1)au from this time and mark, historically, the transition from the conceptually driven art projects of the 1960 s to their spectacular built works of the early 1980 . The uneasy tension between the processes of art and architecture is captured in the emotion of the act itself, the thinly veiled animosity towards the architectural object. It is also captured through the medium by which the act is orchestrated: the model which bridges the gap between the work of art and architecture. At the same time as the firm were developing these destructive tactics in models and gestures, they were formulating the blueprint for an architectural design process that, drawing heavily from artistic process, became the framework for their work throughout the 1980 s. Embodied in their 'psychogram', the partnership actively promoted the reduction of design to a singular, highly emotive sketch and model that were undertaken simultaneously by respective members of the team. The gesture in itself was a violent one, with many of the drawings of 'psychograms' demonstrating not only the speed of the drawing but the emotion, even anger, pulsing through the hand which draws it. While emphasising speed, the gesture of the psychogram is, like the projects themselves, an act of violence.

The 1979 manifesto which accompanies the Vector Haus project makes clear the connection between making architecture and physical, often bodily and even murderous violence. Entitled the 'Poetry of Desolation' the text is significant. It reads:

'If there is a poetry of desolation, then it is the aesthetics of the architecture of death in white sheets. Death in tiled hospital rooms. The architecture of sudden death on the pavement. Death from a rib-cage pierced by a steering shaft. The path of a bullet through a dealer's head on 42 nd Street. The aesthetics of the architecture of the surgeon's razor-sharp scalpel. The aesthetics of peep show-sex in washable plastic boxes, of the broken tongues and the dried up eyes. And that is how the buildings have to be. Unpleasant, rough, pierced. Blazing. Like an erected angel of death.'

Replacing the positivistic values of architectural space with the 'unpleasant, rough and pierced' entrails of this poetry of desolation enables Coop Himmelb(l)au to develop an automated model of violence which is central to their work and the processes used to create it. As well as being antihumanist, the process is in its nature avant-garde, distancing itself from the forces of normalisation and conformity which are embodied in the traditional processes of architectural design and the inevitably sanitised products of this process. The unglamorous realities of this anti-architectural method are embodied in Vektor Haus II where the dagger not only tears open the skin of the building, but its internal spaces, its programme, its history, its memories and its values. As the object of accumulated values, the building is attacked as a means of attacking these values. 


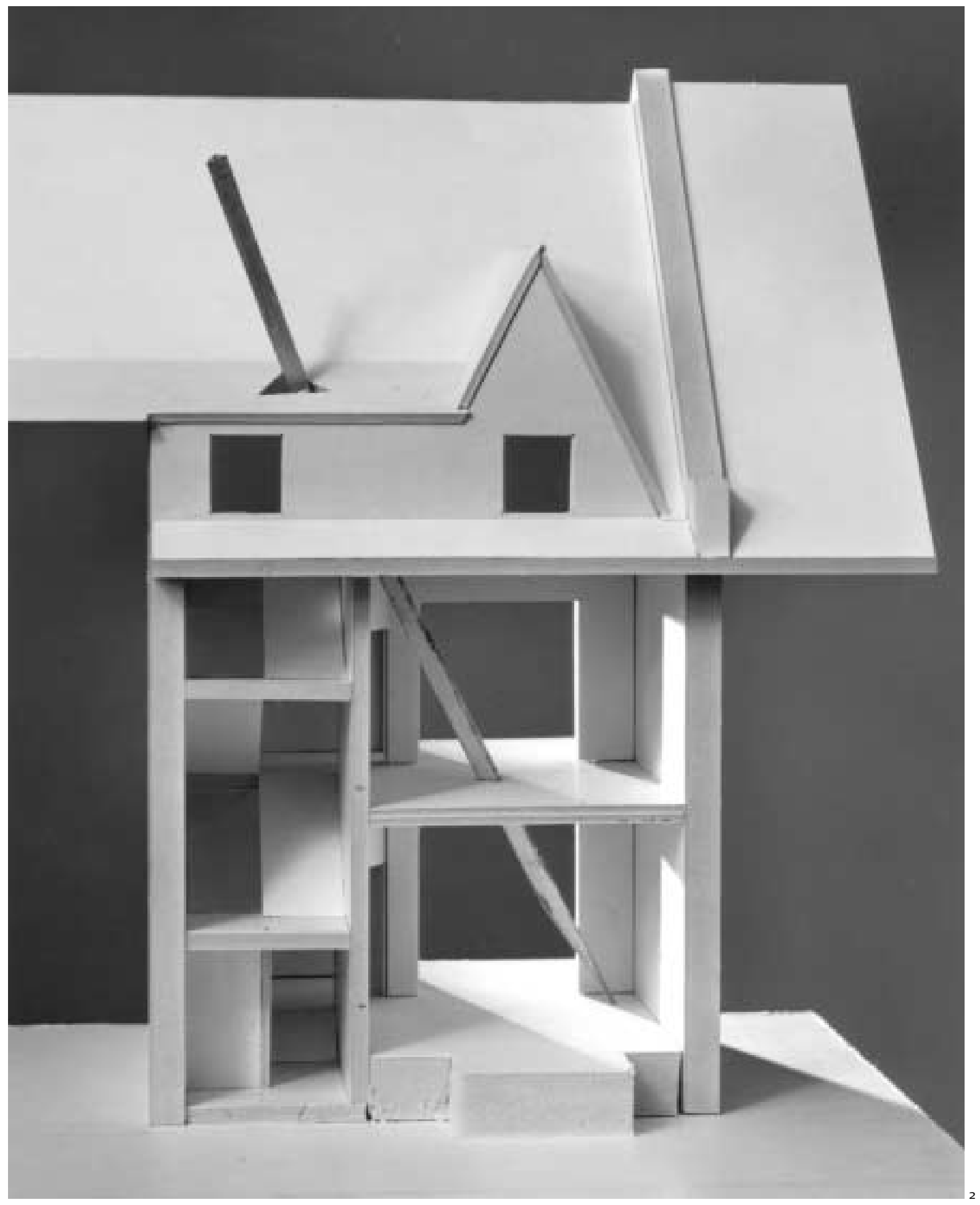

\section{Himmelb(I)au and the historical 'avant-garde'}

The emergence of these critical practices in Coop Himmelb(1)au's work in the late 196os and '7os, while not confined to their work alone, aligns the practice's work with the processes and critical debates happening in critical art theory at the time, embodied in the collective impetus that contemporaneous critics termed the 'neo-avantgarde' to denote the resurgence of ideas originally explored in the 'historical' avant-garde of the 1930s. ${ }^{10}$ The relationship between the working method of Coop Himmelb(l)au and the historical avant-garde is well established, particularly in relation to the
2 Vektor II, unbuilt project
Russian Constructivists, ${ }^{11}$ the German

Expressionists $^{12}$ and the later Surrealist movement. Michael Sorkin links the work of the firm with recognised members of the Surrealist movement such as Friedrich Kiesler and Kurt Schwitters, directly linking their architectural process with the automatism of Breton, a connection also made by Wolf Prix himself. ${ }^{13}$ However the processes of making that emerge in the architectural practices of Coop 
Himmelb(1)au in the '6os and '7os have the most pervasive resonances with the violent strategies in art-making first explored in the Dada movement where the connection between art objects and social values was first articulated and attacked. Dada grew out of the pessimism associated with the First World War and, blaming the violence of the War on bourgeoisie values, attacked the art object as the most obvious and tangible extension of bourgeoisie taste. In the experimental work of Dadaism the act of making art, its representation, and the manifesto work in conjunction to establish a framework for critical practice; in this case a practice against all systems of value and normalisation. These processes were inherently violent, and based on barely concealed nihilistic tendencies emerging from the brutality of the First World War.

Dada, as the antithesis of art, was inherently destructive in its objectives as well as its processes. Tristan Tzara, for instance wrote that ' $[\mathrm{a}] \mathrm{s}$ Dada marches it continuously destroys, not in extension but in itself' ${ }^{14}$ In his Dada Manifesto from 1918 he proclaimed that Dada was 'a protest with the fists of its being engaged in destructive action' ${ }^{15}$ Some of these processes were literally destructive, with strong affiliations with the stabbing, ripping and tearing tendencies that occur in Himmelb(l)au's projects several decades later. ${ }^{16}$ However Dada, as well as dismantling architectural objects in violent ways, provided lasting models for artistic activity which are still influential and widely used. Methods such as collage, Max Ernst's process of 'frottage' and photomontage all emerged in a very brief period as part of the artistic aims of the movement. ${ }^{17}$ Central to the evolution of these processes was the notion of indeterminacy as artists increasingly sought to distance themselves from the work of art and the accumulated bourgeoisie values embedded in it. Foremost in this process were the collages of Hans Arp. Arp tore up pieces of coloured paper and scattered them on the ground, later gluing them in place to make abstract compositions of colour which, he argued, were more meaningful than compositions he had deliberately arranged. Arp wrote of this procedure:

'[...] often I shut my eyes and chose words and sentences in newspapers by underlining them with a pencil. I called these poems "Arpaden" [...] We thought to penetrate through things to the essence of life, and so a sentence from a newspaper gripped us as much as one from a prince of poets. ${ }^{18}$

Replicated in the poetry of Tzara and other Dada poets, Duchamp also embraced similar processes of indeterminacy, generating curves in his large glass from a ruler made by dropping a metre length of string from the height of a metre. Ernst dismantled the art-object through frottage, a process where he wrapped an object with paper and then used this to generate later artworks. Coop Himmelb(1)au's Groninger Musuem, where the 'psychogram' literally wraps the architectural object, can be seen as the inversion of this process where the object rather than generating the drawing, is generated by it.

Arp's process of collaging, also undertaken with closed eyes, has a relationship, at least in terms of process, to Coop Himmelb(1)au's 'psychogram' where the creative moment and the act of making is accelerated into a singular, uncontrollable moment. ${ }^{19}$ As these processes emerged in Dada they also became, like the 'psychogram', increasingly violent as instantaneity became the datum against which works were measured. Often involving dropping sharp objects from a height, throwing darts at a wall, tearing, ripping and slicing, the bodily act of violence becomes the art object, as the artist tears, rips, slices and shreds at the material fragments that compose it.

\section{Himmelb(I)au as resurgent 'avant-garde'}

Obvious connections exist between the theoretical agendas of Dada and Coop Himmelb(1)au. However while these connections between the strategies of making in Coop Himmelb(1)au's work and the historical avant-garde have been suggested, what is less explored is the connection these practices might have with the neo-avant-garde of the 196os, which, in the work of a number of artists, resurrected the radical themes of Dada and particularly the processes of making that were central to it. Artists like Andy Warhol had already explored the notions of aestheticised violence in paintings like his 'disaster' series from the early 196os, while contemporaries like Dan Flavin and Jasper Johns used the idea of the 'ready-made' to critique commercialisation and originality as themes of a broader existential oriented nihilism. Conceptual art, which dominated the art of the late 196os and early '7os, borrowed heavily from Duchamp shifting emphasis dramatically from the art object, to the conceptual idea. The Dadaist practices explored in Himmelb(l)au's work also became important elements of avant-garde artistic production in the same period.

Coop Himmelb(1)au's arrival on the architectural scene in the late 1960 s coincided with a resurgence of avant-garde practices in architecture (through the work in Europe of Archigram, Superstudio and Archizoom) and, simultaneously, the moment when established critical notions of the avant-garde were being revisited and scrutinised. ${ }^{20}$ Manfredo Tafuri had radically repositioned the critical limitations of an avant-garde in architecture in the late 196os and throughout the ' 7 os arguing, perhaps gloomily, that the project of Modernism was complicit with a bourgeois capitalist agenda which eventually either absorbed individual practitioners or drove them into isolated experimentation. The twin operations of Tafuri's polemic are embodied in the rationalist pursuit of the object and the labyrinthine obsession of the avant-garde to undermine it. Both are, for Tafuri, ineffective practices for resisting the hegemony of capitalist production and have been linked to the early work of Coop Himmelb(1)au. ${ }^{21}$ The criticism of Tafuri against this socially impotent 'neo-avant-garde' and its tendency to reaffirm rather than challenge a bourgeois status quo was replicated in art theory in the late 1960s and early '7os, particularly in the work of critic Peter Bürger. ${ }^{22}$ For 
Bürger the historical art processes of Dada were engaged with a critique of the autonomy of art, seeking to reconnect art with the practices of life by dismantling bourgeois social values. As a result, Bürger argues, paralleling Tafuri's thesis, that the neo-avant-garde was no longer involved in critiquing the autonomy of art, but reaffirming it, and in particular its relationship to capitalist production. ${ }^{23}$ For Bürger this was the end of art as a critical practice.

As a critical practice which sets out violently from its inception to dismantle the forms of capitalist hegemony in architectural production, the antiavant-garde positions of Bürger and Tafuri are of direct relevance to the work of Coop Himmelb(1)au and its relationship to the processes of Dada. The sceptical attitude towards avant-garde practice embodied in the writings of Bürger and Tafuri has recently been radically repositioned by poststructuralist reappraisals which question the historically overdetermined framework through which avant-garde practices have been understood. The work of recent art theory has established a less linear model of historical evolution whereby the positivistic values of the historical avant-garde are no longer the 'origin' of art, and its nihilistic collapse in the neo-avant-garde is no longer its endpoint. Foremost among the polemical re-readings of the 1960s avant-garde is Hal Foster's The Return of the Real (1996) which uses Bürger's thesis as the point of departure for reinvigorating the practices of the neoavant-garde and their broader relationship to the history of art and architecture. ${ }^{24}$ Drawing from what he identifies as contextual flaws in Bürger's selective and linear historical reading of the avant-garde, Foster presents an alternate model for understanding the neo-avant-garde, which is not the nihilistic end of art, but instead the emergence of new forms of critical practice which are responding to different and ephemeral conditions in broader culture. ${ }^{25}$ The neo-avant-garde of the 1960 , for Foster at least, didn't replicate the historical avant-garde but reappropriated it to develop new practices of critical activity. For Foster, the neo-avant-garde represents a continuation of these practices in a new critical context which, by targeting cultural values outside the domain or art, is 'enact[ing] its project for the first time'. ${ }^{26}$

\section{Making and critique}

Following Foster's argument, the relationship between the object and its author in Dada and in Coop Himmelb(1)au becomes critical, representing divergent tactics and outcomes despite similar artistic processes. Dada used the object to celebrate bourgeois values, introducing the undesigned object into art primarily due to its radical and violent historical disconnection from it. Through this displacement, enacted in the readymades of Duchamp, the frottage of Ernst, the contorted collages of Arp and even the dissected newspaper poetry of Tzara, the object is representative of the critique, constituting in itself an assault on the institution of art. While Coop Himmelb(l)au introduce identical processes to Dada - frottage in Groningen, collage and indeterminacy through the psychogram, photomontage through the urban proposals of the early 1970s - the relationships are inverted, dismantling the undesigned object, rather than edifying it in the model of Dada. The 'object' in Himmelb(l)au's work is not the antithesis of bourgeois values, as found in Dada, but instead the accumulation of capitalistic values. The fluid nature of the values assigned to these objects is also implicated in the mechanisms through which violence is mediated through the work constituting, in Dada, a bracketed assault on art-making and, in Coop Himmelb(1)au a full-frontal assault on the accumulated objects of economic rationalisation. In this context the acts of making architecture that were embodied in the early practices of Coop Himmelb(l)au are not the impotent historical recurrence of the themes of Dada against established bourgeois values but instead, in the model of Foster's analysis, the appropriation of these practices against new forces, enacting in the process this model of critique for the first time.

By critiquing the historical processes of making architecture and their inherent complicity with economic systems (rather than the institution of art itself), the image of the Vektor Haus II project can be repositioned as the crystallisation of this moment in the firm's work, before it became inevitably entwined with the forces it set out to critique. The assault on the object launched in the Vector Haus project represents an emancipatory act, freeing the designer from the burdens of conventional design and, at the same time, bridging the processes of making art with the prospect of a critical practice in architecture. This is despite the fact that in the recent work of the practice, conducted on vast scales with lavish architectural budgets, this critique of the acts of making is no longer present and in fact has, as Tafuri and Bürger predict, become inevitably consumed by capitalist modes of production. Processes of making in these works are not critiqued but rather embodied in the making which becomes, rather than the 'eyes-shut' instantaneous sketch, a process of increasingly visual strategies of seduction, reducing the violence implicit in their original manifestoes to an aestheticised model of visual representation. As the process of making becomes embodied in the object, the role of making as a critical practice dissolves. Devoid of the antiarchitectural critique which accompanied their avant-garde projects of the 1970 , it is easy to see, as Werner has illustrated, how the labyrinthine interiors of Coop Himmelb(1)au's most recent work are connected with Piranesi's own vision and can be seen, in the context of Tafuri's critique, to constitute a nihilistic, internalised and self-perpetuating system of architectural production. In this system the objects that were attacked in their earlier projects are perpetuated in reality, with the help of rapid prototyping machines and computer visualisation. It is within this context that the single image of Vektor Haus II becomes pertinent, not only linking the early work of the firm with avant-garde 
strategies of art-making, but also celebrating the internalised frictions that exist within the work of Coop Himmelb(1)au and their earliest theoretical aspirations. As the lasting symbol of violence, nihilism and emotion in Himmelb(1)au's work, and re-enacting in built space the murderous tactics of Dada, the Vector Haus II is representative of an isolated and historical moment in a complicated and evolving architectural process where making became not the object or its representation but the act itself.

\section{Notes}

1. The act of piercing a building is replicated in a similar project from the same year where a glistening aluminium shard is stabbed through the centre of a historic nineteenth-century building: Joseph Olbrich's Vienna Succession Exhibition building which embodied the turn-of-the-century values of progressive Austrian architecture. Coop Himmelb(1)au, Architecture is Now: Projects, (Un)buildings, Actions, Statements, Sketches, Commentaries 1968-1983 (New York: Rizzoli, 1983).

2. Lucy R. Lippard, Six Years: The Dematerialisation of the Art Object from 1966 to 1972 (Berkeley: University of California Press, 1997); Rosalind E. Krauss, The Originality of the Avant-Garde and Other Modernist Myths (Cambridge MA: The MIT Press, 1986), pp. 1-6.

3. Duchamp wrote: 'whether Mr Mutt with his own hands made the fountain or not has no significance. He CHOSE it. He took an ordinary article of life, placed it so that its useful significance disappeared under the new title and point of view - created a new thought for the object'. Quoted in Matthew Gale, Dada and Surrealism (London: Phaidon, 1997), p. 103.

4. Philip Johnson and Mark Wigley, Deconstructivist Architecture: The Museum of Modern Art, New York (Boston: Little Brown, 1988).

5. Anthony Vidler, 'The Building in Pain: The Body and Architecture in Post-Modern Culture', AA Files, 19 (Spring 1990), 3-10. Later recast as a chapter in: Anthony Vidler, The Architectural Uncanny (Cambridge MA: The MIT Press, 1992), pp. 69-82.

6. Coop Himmelb(1)au, 'Architecture Must Blaze', (1980) in Wolf D. Prix, Get Off My Cloud: Coop Himmelb(l)au Texts 1968-2005, ed. by Martina Kandeler-Fritsch and Thomas Kramer(Ostfildern-Ruit: Hatje Cantz, 2005), p. 46.

7. Wolf D. Prix, 'And This Is How It Works', in Prix, Get Off My Cloud, p. 45; Coop Himmelb(1)au, 'The Dissipation of Our Bodies in the City', in Die Faszination der Stadt/The Power of the City (Darmstadt: Verlag Jürgen Häusser, 1992), pp. 12-19.

8. Strong connections exist between these acts of masculine insecurity and Freud's writing on castration anxiety. Gunther Feuerstein finds in these acts: 'a violent symbol of deflowering and penetration' and for Frank Werner they constitute 'in the Freudian sense as more or less violent erotic displacement activities'. Frank Werner, Covering + Exposing: The Architecture of Coop Himmelb(l)au (Bäsel: Birkhäuser, 200o), p. 43.

9. Wolf D. Prix, 'Our Architecture has Four Cities and Seven Lives', in Prix, Get Off My Cloud, p. 63.

10. A term popularised by Peter Bürger in Theory of the Avant-Garde (Minneapolis: University of Minnesota Press, 1984) [first published in 1972]. It has recently been widely used in art theory, particularly in the work of American authors such as $\mathrm{Hal}$ Foster, Benjamin Buchloh and Branden Joseph.

11. Johnson and Wigley, Deconstructivist Architecture; Mary McLeod, 'Architecture and Politics in the Reagan Era: From Post Modernism to Deconstructivism', Assemblage, 8 (February 1989), p. 44. 12. Werner, Covering + Exposing, pp. 56 \& 64; McLeod, 'Architecture and Politics in the Reagan Era', p. 44.

13. Michael Sorkin, Exquisite Corpse: Writing on Buildings (London: Verso, 1991), pp. 339-52; Wolf Prix, 'Our Architecture has Four Cities and Seven Lives', Prix, Get Off My Cloud, p. 63 .

14. Tristan Tzara, 'Lecture on Dada' (1922), quoted in Robert Motherwell ed., The Dada Painters and Poets: An Anthology (Cambridge, Massachusetts: The Belknap Press, 1979), p. 251.

15. Tristan Tzara, 'Dada Manifesto' (1918), quoted in Motherwell ed., The Dada Painters and Poets, p. 81.

16. Dada's contempt for the art object was famously demonstrated in the 1920 exhibition held in Cologne in the unglamorous spatial backrooms of the Winter Brewery. Showcasing the work of Max Ernst and Johannes Baargeld (the pseudonym of Alfred Grünwald), the exhibition entitled Dada Early Spring contained a wooden sculpture by Ernst accompanied with a hatchet mounted on the wall inviting viewers to destroy the parts of the sculpture they didn't like. Baargeld's nearby Fluidoskeptrik, containing a fishbowl full of blood and human limbs, was also destroyed in the process. See Georges Hugnet, 'The Dada Spirit in Painting' in
Motherwell ed., The Dada Painters and Poets, p. 161.

17. As part of this push towards instantaneous composition, the Dada movement invented the use of photomontage, attracted to it for its political appeal as well as its ability to capture the dynamic and random energy of the city.

Photomontage is also a medium appropriated by Coop Himmelb(1)au where images are violently torn, ripped and shredded and then reassembled as footprints for architectural form. Coop Himmelb(1)au, 'The Dissolution of Our Bodies in the City' in Coop Himmelb(1)au, Die Faszination der Stadt, p. 12.

18. Hans Arp, quoted in Gale, Dada and Surrealism, p. 87.

19. The Surrealists equally associated the act of closing the eyes with automatism, somehow enabling a direct stream to the unconscious. A famous image by René Magritte entitled Je ne vois pas la [...] cachée dans la foret [I do not see the hidden in the forest] shows the leading members of the movement photographed with their eyes closed further reinforcing this connection with a non-visual model of artistic production. See ed. by Mary Ann Caws, Surrealism (London: Phaidon, 2004), p. 76.

20. Renato Poggioli was the first to promote a theory of the avantgarde in 1968, the same year as Coop Himmelb(l)au's earliest manifestoes. Renato Poggioli argued for the avant-garde as a driving force in every dimension of modern culture: The Theory of the Avant-Garde (Cambridge MA: The Belknap Press, 1968); Jochen Schulte-Sasse, 'The Theory of Modernism versus Theory of the Avant-Garde', in Bürger, Theory of the Avant-Garde, pp. vii-lv.

21. Frank Werner links Coop Himmelb(1)au's working method in particular with Tafuri's writing on experimental methods which informs his theory of 'operative criticism': Manfredo Tafuri, Theories and History of Architecture (London: Granada, 1980); Susan Carty Piedmont, 'Operative Criticism,' JAE 40, 1 (Autumn, 1986), 8-13. However, Tafuri distinguishes between these experimental methods and a truly avant-garde approach to architectural production which seeks to 
dismantle existing models of architectural making rather than building on them: Werner, Covering +Exposing, pp. 156-158.

22. In his influential 1974 work Theory of the Avant-Garde, Bürger argued that the 1960 s had witnessed the emergence of a neo-avant-garde in art which resurrected, in a depoliticised sense, the strategies and procedures of the 'historical avant-garde' of the 1920s and '3os. Bürger argued that this resurrected avant-garde concealed a cultural and artistic impotency which was complicit with the end of art and its resignation to capitalism. Bürger, Theory of the Avant-Garde.

23. Tafuri and Bürger's theses, in the context of the work of Coop Himmelb(1)au, both use a Marxist reading of history to position, perceiving fatalistically the collapse of their respective disciplines in roughly equivalent periods of time, arguing that their resurrection through the avantgarde, is in fact the last stages of their demise. Bürger endows the historical avant-garde with positivistic values where for Tafuri, however, all avant-garde activity is flawed. Schulte-Sasse, 'Theory of Modernism versus Theory of the Avant-Garde'; Bürger, Theory of the Avant-Garde: vii-lv.

24. Hal Foster, The Return of the Real: The Avant-Garde at the End of the Century (Cambridge MA: The MIT Press, 1996).

25. Benjamin Buchloh's work on positioning the neo-avant-garde in an expanded context is also relevant here. Buchloh stresses the role of the institution in mediating this historical slippage: Benjamin Buchloh, Neo-Avantgarde and Culture Industry: Essays on European and American Art from 1955 to 1995 (Cambridge MA: The MIT Press, 2003).

26. Foster, The Return of the Real, p. 20.

\section{Illustration credits}

arq gratefully acknowledges:

Margherita Spiluttini, 1

Coop Himmelb(1)au, 2

\section{Biographies}

Michael Chapman is currently undertaking a PhD in Architecture at the University of Newcastle (Australia) where he is employed as a Research
Assistant, Design Tutor and part-time Lecturer. He has written widely on aspects of architectural theory and their relationship to art practices.

Michael J. Ostwald is Dean of Architecture at the University of Newcastle (Australia), a Visiting Professor at RMIT University and a Professorial Research Fellow at Victoria University Wellington (New Zealand). He has written extensively on contemporary architectural theory and its relationship to science and mathematics.

\section{Authors' addresses}

Michael Chapman

School of Architecture and Built

Environment

The University of Newcastle NSW

Australia 2308

michael.chapman@newcastle.edu.au

Prof. Michael Ostwald

School of Architecture and Built

Environment

The University of Newcastle

NSW

Australia 2308

michael.ostwald@newcastle.edu.au 